\title{
Research on the Study of Learning Topics, and Life Adaptation of Middle-Aged and Elderly People
}

\author{
Yen-Ni, Tsai ${ }^{1, a}$ \\ ${ }^{1}$ The Education Science Department Zhaoqing University Zhaoqing city, China \\ aypwaittim@163.com
}

\begin{abstract}
The purpose of this study was to investigate the demographic attributes of middle-aged and elderly people, the effect of middle-aged and long-term perspectives, and the influence of middle-aged and older Learning Topics on their life adaptation. This study used a questionnaire survey method for participants who participated in lifelong learning in Taiwan. Data processing and analysis were performed through statistical methods such as descriptive statistics, t-test, and single-factor variance analysis. The study found that: 1 . the middle-aged and elderly people have a good analysis of the differences in Learning Topics; 2 . the middle-aged and elderly people have significant results in the education, age and region for the differences in the Proactive ability; 3 . the middle-aged people with different population attributes are living. The difference analysis of adaptation has reached significant results; 4 . The learning theme and prospective force of middle-aged people have predictive ability due to the relationship with life adaptation. Finally, based on the results of this study, a number of relevant recommendations are made for middle-aged learners and follow-up researchers for reference.
\end{abstract}

Keywords: Learning Topics, Proactive ability, life adaptation

\section{INTRODUCTION}

According to Gan, Hu \& Zhang (2010) [1] indicates that a person's forward-looking response is an attitude in which an individual can prepare for the future before an event or stress occurs. Generally speaking, the life experience of middle-aged and old age has reached a comprehensive level. It is understandable to pursue the ideal life in the later stage. The forward-looking response is more influencing the adaptation of life, especially in the post-retirement learning state, and the older learners hope or learn more. The theme, the pursuit of post-planning, and even the second spring of the career, is enough to cope with the new life after retirement. This is just as the scholars McClusky (1987) [2] put forward the concept of "five levels of demand" and Maslow (1971) [3] "the five levels of human needs." Theory, which plays an important role in the later life of middle-aged and elderly people, so it is necessary and important to explore the forward-looking and Learning Topics of middle-aged learners.

\section{Research Purposes}

Sohl \& Moyer (2009) [4]believes that forward-looking is a risk management perspective that avoids predictable and unpredictable stress and harms the future. Now the average life expectancy has increased. Because of the improvement of medical technology and the improvement of living standards, the nutrition and sanitation environment is gradually improving. The late life of middle-aged people should have forward-looking views and thinking before they can choose the subject of interest and improve. Adaptation of life in later life. The main purposes of this study include:
(1) Analysis of differences in Learning Topics among middle-aged and older people with different demographic attributes;

(2) Exploring the differences in the forward-looking response of middle-aged people with different population attributes;

(3) Exploring the differences in the adaptation of the middle-aged and elderly people with different population attributes;

(4) Exploring the relationship between the learning theme and prospective force of middle-aged people in response to life adaptation. 


\section{Research Method}

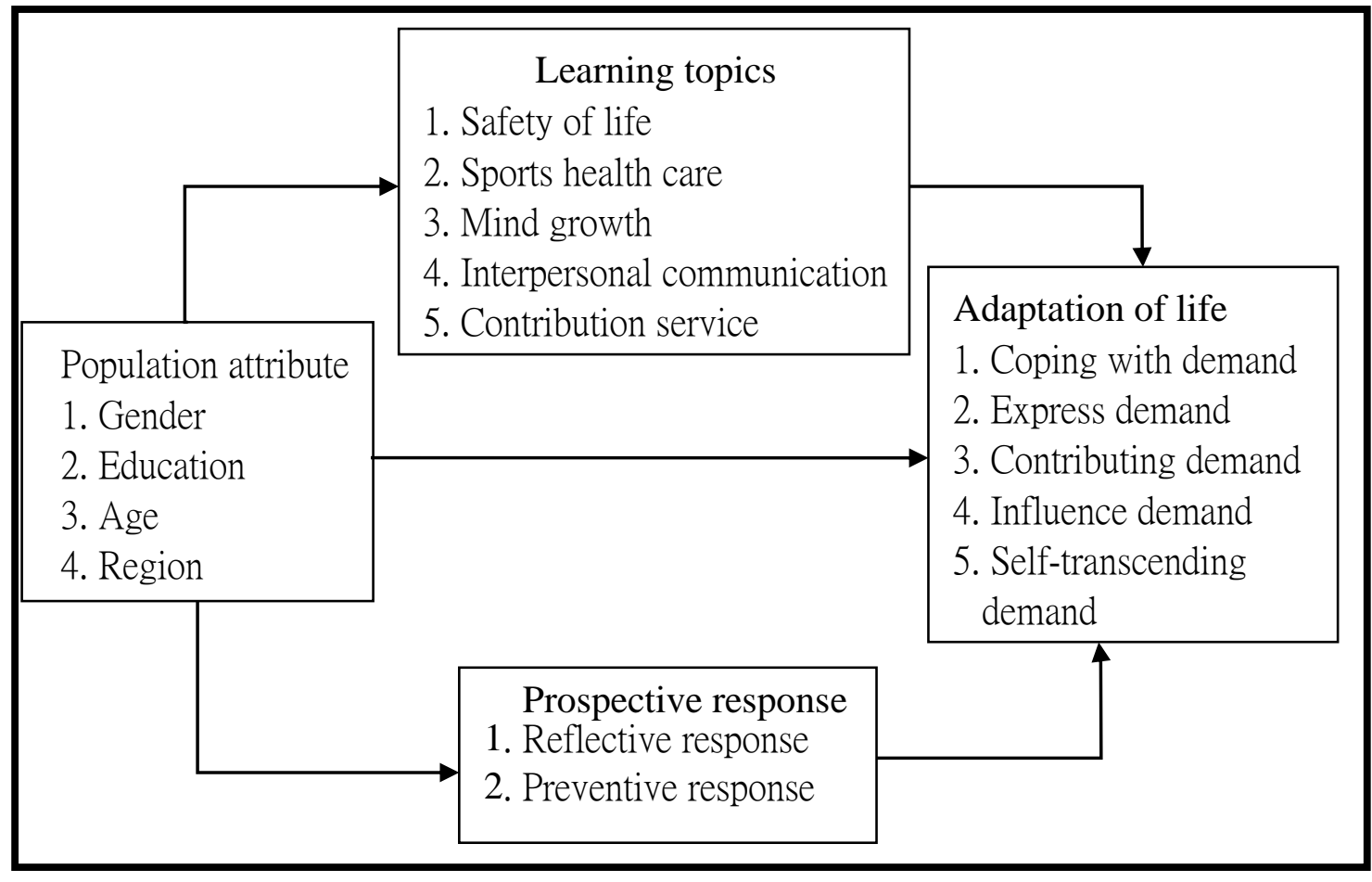

Figure 1 This study architecture

\subsection{Research Hypothesis}

According to the research structure, the research hypotheses established in this study are as follows:

Hypothesis 1: Population attributes have a significant relationship to middle-aged Learning Topics

Hypothesis 2: Population attributes have a significant relationship with the medium- and high-age Proactive ability Hypothesis 3: Population attributes have a significant relationship to middle-aged life adaptation

Hypothesis 4: Middle-aged Learning Topics and prospects for predicting life adaptation

\subsection{Research Variable}

The self-variation part is "population attribute": (1) Gender: The gender of the subject is divided into two categories: "male" and "female". (2) Education: Refers to the academic qualifications in Taiwan. The study is divided into four categories: "National Small", "National Middle School", "High School" and "College or above". (3) Age: The current age category of the subject. It is divided into four categories: "45-49 years old", "50-54 years old", "55-59 years old" and "60 years old or older". (4) Area: refers to the division of administrative areas in Taiwan. It is divided into three categories: "the Mountain Line Area", " the Coast Line Area" and " the Tun District".

The variables are "forward-looking", "learning theme" and "life adaptation". In the Operational Definition and Measurement Tools section: (1) the definition of the mediumand high-age Proactive ability: the main study is based on the "Foresight Response Initial Assessment Table" in Chapter 6 of Professor Wei, Hui-Chuan's “Adult Education Administration Program Development" (2015) [5]. The tools used the survey assessment form to collect information and summarized two facets for analysis. They were "reflection response" and "prevention response", and adopted semi-structured interview guidelines for information. (2) Definition of the learning theme of middle-aged and older students: Based on the reference to the "Active Ageing Learning Subject Checklist" in the fifth chapter of Professor Wei, Hui-Chuan's “Adult Education Administration Program Development" (2015), the main research tools are summarized. In the face of analysis, they are "life safety", "sports health care", "spirit growth", "interpersonal communication" and "contribution service". From the subjective experience of the respondents, they predict their Learning Topics. Select. (3) Definition of middle-aged life adaptation: Based on the reference to the "Elderly Career Learning Needs Assessment Needs Checklist" in the fifth chapter of Professor Wei, Hui-Chuan's "Adult Education Administration Program Development " (2015), the main research tools are summarized. The analysis of the facets is "funding demand", "expression demand", "contribution demand", "impact demand" and "self-transcend demand". From the subjective choice of respondents, we predict the actual idea is generated.

\subsection{Research Object}

This study used a high-age university in central Taiwan as a research site, and adopted a purposive sample, supplemented by snowball sampling to seek research cases (Zhang Shaoxun, 2003) [6], and adopted a medium-aged person for forward-looking and Learning Topics. Life adapts to the most suitable ethnic group (Settersten, 2006) [7], with 239 males 
and 161 females. The sample selection conditions are as follows: (1) the number of genders is not limited; (2) the age between 45 and 65 years old; (3) active motivation for learning; (4) the case can communicate in Mandarin or Taiwanese And the writer; (5) the degree of education is limited to the national level; (6) the person who voluntarily accepts the scale survey.

\section{RESEARCH RESULT}

\subsection{Analysis of Differences in Learning Topics among Elderly People with Different Demographic Attributes}

\section{(1) Gender:}

Based on the statistical values of the questionnaire, this study found that gender has a significant impact on learning topics (Boaz, Hayden \& Taylor, 2000). In the gender component, the number of males is 239 , the average is 3.785 ; the female is 161 , and the average is 3.882 . In the independent sample $t$ test, $\mathrm{p}<0.05$ was used as a significant level. An independent sample $\mathrm{t}$ test of "life safety" was found to be $\mathrm{p}=0.005$, $\mathrm{p}<0.002$ for the independent sample $t$ test of "interpersonal communication", $p=0.000$ for the independent sample $t$ test of "contribution service", all of which reached a significant level.

\section{(2) Education}

This study found that there is no difference in the degree of learning topics. In the academic part, the number of small people is 95 , the number of people in the middle is 171 , the number of high school is 107, and the number of college or above is 27 . In the analysis of single-factor variance, $p<0.05$ was used as a significant level, and $\mathrm{p}=0.000$ for "sports health care" ANOVA, $p=0.000$ for "soul growth" ANOVA, $p=0.000$ for "interpersonal communication" ANOVA, "contribution" The service "ANOVA's $p=0.000$ " has reached a significant level. After further examination by Scheffe, it was found that the above-mentioned people in colleges and universities are more concerned with "sports health care" than those in the national, middle and high schools. In addition, people in the middle school pay more attention to "sports health care" than those in small and high schools. People pay more attention to "sports health care" than those in high school. People above junior colleges pay more attention to "spiritual growth" than those in middle schools and high schools. In addition, people in small and medium-sized countries pay more attention to "spiritual growth" than those in high schools. People pay more attention to "interpersonal communication" than those in middle schools and high schools. In addition, people from higher vocational colleges and colleges attach more importance to "interpersonal communication" than those in high school. People above junior colleges pay more attention to "contributing" than those from small, middle and high schools. "Services", in addition, people in small and medium-sized countries pay more attention to "contributing services" than those in high schools.

(3) Age

The study found that there are still differences in the degree of learning topics. In the age group, the number of people aged $45-49$ is 121 , the number of people aged 50-54 is 159 , and the number of people aged 55-59 is 107 . The number of people over the age of 13 is 13 . In the single factor variance analysis, $\mathrm{p}<0.05$ was used as a significant level. Found $\mathrm{p}=0.000$ for "Life Safety" ANOVA, $\mathrm{p}=0.000$ for "Sports Health Care" ANOVA, $p=0.000$ for "Psychic Growth" ANOVA, 0.000 for "Interpersonal Relationship" ANOVA, $\mathrm{p}=0.000$ for "Contribution Service" ANOVA. Both have reached a remarkable level. After further examination by Scheffe, it was found that people over the age of 60 pay more attention to "life safety" than those aged 45-49, 50-54 and 55-59, and 45-49 and 55-59 years old. People who are 50 to 54 years old pay more attention to "life safety"; people aged 55 to 59 pay more attention to "sports health care" than people aged 45 to 49 and 50 to 54 years old; people over 60 years old are 45 to 49 years old, People aged 50-54 and 55-59 pay more attention to "spiritual growth"; people aged 55-59 and over 60 pay more attention to "interpersonal communication" than those aged 45-49 and 50-54, and another 60-year-old The above people pay more attention to "interpersonal communication" than those aged 55-59; people aged 45-49 and 55-59 pay more attention to "contribution services" than those aged 50-54 and over 60 .

(4) Area

The study found that there are still differences in the degree of learning topics. In the regional part, the number of people in Shan County is 91, the number of people in the sea area is 108 , and the number in the Tun District is 201. In the single factor variance analysis, $\mathrm{p}<0.05$ was used as a significant level. Found $\mathrm{p}=0.000$ for "safety of life" ANOVA, $\mathrm{p}=0.000$ for "sports health care" ANOVA, $\mathrm{p}=0.035$ for "spiritual growth" ANOVA, $\mathrm{p}=0.000$ for "interpersonal communication" ANOVA, $p=0.000$ for "contribution service" ANOVA, all have reached a remarkable level. After further examination by Scheffe, it was found that the people in Coast Line Area and Handan District paid more attention to "life safety" than those in Shan County. People in Shan County and Coast Line Area paid more attention to "sports health care" than those in the Tun District. People in the county area pay more attention to "spiritual growth" than people in the Tun District. People in Coast Line Area and Qufu District pay more attention to "interpersonal communication" than people in Shan County. People in Mountain Line Area and Coast Line Area are more likely than people in Qufu District. Pay attention to "contribution services." The results of the analysis of differences in learning topics among middle-aged people with different demographic attributes are presented in Table 1.

Table 1 Analysis of differences in learning topics among middle-aged and older people with different population attributes

\section{Panel A: Gender}

\begin{tabular}{lllll}
\hline Differences in learning $\begin{array}{l}\text { Male } \\
\text { topics }\end{array}$ & \multicolumn{2}{c}{ Female } & Difference \\
\cline { 2 - 5 } & Number of people & Average Value & $\begin{array}{l}\text { Number of } \\
\text { people }\end{array}$ & Average Value \\
\hline
\end{tabular}




\begin{tabular}{llllll}
\hline Safety of life & 239 & 4.31 & 161 & 4.14 & $\mathrm{M}>\mathrm{F} * *$ \\
\hline Sports health care & 239 & 3.10 & 161 & 3.29 & \\
\hline Mind growth & 239 & 3.79 & 161 & 3.93 & \\
\hline $\begin{array}{l}\text { Interpersonal } \\
\text { communication }\end{array}$ & 239 & 4.21 & 161 & 4.42 & $\mathrm{~F}>\mathrm{M} * *$ \\
\hline Contribution service & 239 & 3.58 & 161 & 3.92 & $\mathrm{~F}>\mathrm{M} * * *$ \\
\hline Learning topics & 239 & 3.78 & 161 & 3.88 & \\
\hline
\end{tabular}

Panel B: Education

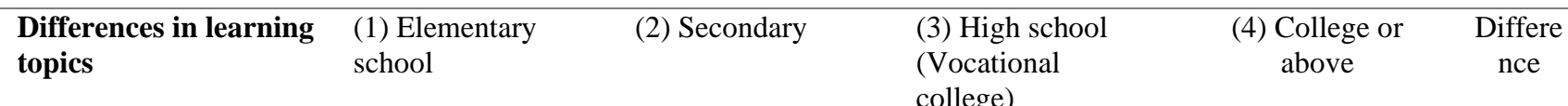

\begin{tabular}{lllllllll} 
& N.P. & A.V. & N.P. & A.V. & N.P. & A.V. & N.P. & A.V. \\
\hline Safety of life & 95 & 4.36 & 171 & 4.1974 & 107 & 4.2091 & 27 & 4.3519 \\
\hline Sports health care & 95 & 3.10 & 171 & 3.44 & 107 & 2.59 & 27 & 4.02 \\
\hline
\end{tabular}

\begin{tabular}{|c|c|c|c|c|c|c|c|c|c|}
\hline & & & & & & & & & $* * *$ \\
\hline Mind growth & 95 & 4.05 & 171 & 3.83 & 107 & 3.57 & 27 & 4.39 & $\begin{array}{l}4>2 、 \\
3 * * * \\
1 、 \\
2>3 * * *\end{array}$ \\
\hline $\begin{array}{l}\text { Interpersonal } \\
\text { communication }\end{array}$ & 95 & 4.58 & 171 & 4.31 & 107 & 3.97 & 27 & 4.48 & $\begin{array}{l}1>2 、 \\
3 * * * \\
2 、 \\
4>3 * * *\end{array}$ \\
\hline Contribution service & 95 & 3.70 & 171 & 3.75 & 107 & 3.42 & 27 & 4.65 & $\begin{array}{l}4>1 、 \\
2 、 \\
3 * * * \\
1 、 \\
2>3 * * *\end{array}$ \\
\hline
\end{tabular}

\begin{tabular}{|c|c|c|c|c|c|c|c|c|c|}
\hline \multicolumn{10}{|l|}{ Panel C:Age } \\
\hline \multirow[t]{2}{*}{$\begin{array}{l}\text { Differences in learning } \\
\text { topics }\end{array}$} & \multicolumn{2}{|c|}{$\begin{array}{l}\text { (1) } 45-49 \text { years } \\
\text { old }\end{array}$} & \multicolumn{2}{|c|}{$\begin{array}{l}\text { (2) } 50-54 \text { years } \\
\text { old }\end{array}$} & \multicolumn{2}{|c|}{ (3) 55-59 years old } & \multicolumn{2}{|c|}{ (4) 60 years old or older } & \multirow[t]{2}{*}{$\begin{array}{c}\text { Differe } \\
\text { nce }\end{array}$} \\
\hline & N.P. & A.V. & N.P. & A.V. & N.P. & A.V. & N.P. & A.V. & \\
\hline \multirow[t]{5}{*}{ Safety of life } & 121 & 4.31 & 159 & 4.04 & 107 & 4.38 & 13 & 5.00 & $4>1$, \\
\hline & & & & & & & & & 2、 \\
\hline & & & & & & & & & $3 * * *$ \\
\hline & & & & & & & & & \\
\hline & & & & & & & & & $3>2 * * *$ \\
\hline \multirow[t]{2}{*}{ Sports health care } & 121 & 2.98 & 159 & 2.89 & 107 & 3.80 & 13 & 3.25 & $3>1 、$ \\
\hline & & & & & & & & & $2 * * *$ \\
\hline \multirow[t]{3}{*}{ Mind growth } & 121 & 3.84 & 159 & 3.72 & 107 & 3.94 & 13 & 4.66 & $4>1$ 、 \\
\hline & & & & & & & & & 2、 \\
\hline & & & & & & & & & $3 * * *$ \\
\hline \multirow{2}{*}{$\begin{array}{l}\text { Interpersonal } \\
\text { communication }\end{array}$} & 121 & 4.11 & 159 & 4.09 & 107 & 4.72 & 13 & 5.00 & 3、 \\
\hline & & & & & & & & & $4>1$ 、 \\
\hline
\end{tabular}




\begin{tabular}{|c|c|c|c|c|c|c|c|c|c|}
\hline & & & & & & & & & $\begin{array}{l}2 * * * \\
4>3 * * *\end{array}$ \\
\hline Contribution service & 121 & 4.06 & 159 & 3.22 & 107 & 4.09 & 13 & 3.33 & $\begin{array}{l}1 、 \\
3>2 、 \\
4 * * *\end{array}$ \\
\hline
\end{tabular}

\section{Panel D: Region}

\begin{tabular}{llllllll}
\hline $\begin{array}{l}\text { Differences in learning } \\
\text { topics }\end{array}$ & \multicolumn{2}{l}{ (1)Mountain Line Area } & \multicolumn{2}{l}{ (2) Coast Line Area } & \multicolumn{2}{l}{ (3) Tun District } & Difference \\
\cline { 2 - 8 } & N.P. & A.V. & N.P. & A.V. & N.P. & A.V. \\
\hline Safety of life & 91 & 3.64 & 108 & 4.46 & 201 & 4.40 & $2 、 3>1^{* * *}$ \\
\hline Sports health care & 91 & 3.42 & 108 & 3.69 & 201 & 2.78 & $1 、 2>3^{* * *}$ \\
\hline Mind growth & 91 & 3.80 & 108 & 4.00 & 201 & 3.79 & $2>3^{*}$ \\
\hline $\begin{array}{l}\text { Interpersonal } \\
\text { communication }\end{array}$ & 91 & 3.75 & 108 & 4.51 & 201 & 4.43 & $2 、 3>1^{* * *}$ \\
\hline \begin{tabular}{l} 
Contribution service \\
\hline
\end{tabular} & 91 & 3.85 & 108 & 3.96 & 201 & 3.52 & $1 、 2>3^{* * *}$ \\
\hline
\end{tabular}

\subsection{Analysis of the Differences in the Proactive Ability of Elderly People with Different Population Attributes}

(1) Gender:

Based on the statistical values of the questionnaire, this study found that gender has a significant impact on Proactive ability. In the gender section, the number of males was 239, the average was 3.641 ; the female was 161, and the average was 3.686. In the independent sample $t$ test, $p<0.05$ was considered as a significant level, and none of them reached a significant level. .

(2) Education

The study found no difference in the degree of Proactive ability. In the education section, the number of small people was 95 , the number of people in the middle school was 171 , the number of high school students was 107 , and the number of college graduates was 27 . In the single-factor variation analysis, $\mathrm{p}<0.05$ was used as a significant level, and the "preventive response" ANOVA $p=0.022$ was found to be at a significant level. After further examination by Scheffe, no significant level was found.
The study found that there are still differences in the extent of Proactive ability. In the age group, the number of people aged 45-49 is 121 , the number of people aged 50-54 is 159 , and the number of people aged 55-59 is 107 . The number of people over the age of 13 is 13 . In the single factor variance analysis, $\mathrm{p}<0.05$ was used as a significant level. It was found that the "preventive response" ANOVA $p=0.000$, which reached a significant level. After further examination by Scheffe, it was found that people aged 45-49, 55-59 and over 60 paid more attention to "prevention" than those aged 50-54, and those over 60 years old were older than 45-49 years old. People aged 55 to 59 pay more attention to "preventive response." (4) Area

The study found that there are still differences in the extent of Proactive ability. In the regional part, the number of Mountain Line Area is 91, the number of Coast Line Area is 108 , and the number of the Tun District is 201. In the single factor variance analysis, $\mathrm{p}<0.05$ was used as a significant level. It was found that the "preventive response" ANOVA $\mathrm{p}=0.000$, which reached a significant level. Further examination by Scheffe found that the people in the Coast Line Area and the Tun District paid more attention to "preventive response" than those in the Mountain Line Area. The results of the analysis of differences in Proactive ability among middle-aged people with different demographic attributes are presented in Table 2. 
Table 2 Analysis of differences in Proactive ability among middle-aged and older people with different population attributes

\begin{tabular}{lcccc}
\hline Panel A: Gender & \multicolumn{2}{c}{ Male } & Female & Difference \\
\hline Proactive ability & \multicolumn{2}{c}{ Number of people } & Average Value \\
\cline { 2 - 5 } & Number of people & Average Value & 161 & 3.52 \\
\hline Reflective response & 239 & 3.46 & 161 & 4.28 \\
\hline Preventive response & 239 & 4.30 & 161 & 3.68 \\
\hline Proactive ability & 239 & 3.64 & & \\
\hline
\end{tabular}

Panel B: Education

\begin{tabular}{llccccccc}
\hline Proactive ability & \multicolumn{2}{l}{$\begin{array}{l}\text { (1) Elementary } \\
\text { school }\end{array}$} & (2) Secondary & \multicolumn{2}{l}{$\begin{array}{l}\text { (3) High school } \\
\text { (Vocational } \\
\text { college) }\end{array}$} & $\begin{array}{c}\text { (4) College or } \\
\text { above }\end{array}$ & Difference \\
& N.P. & A.V. & N.P. & A.V. & N.P. & A.V. & N.P. & A.V. \\
\hline Reflective response & 95 & 3.47 & 171 & 3.40 & 107 & 3.45 & 27 & 3.50 \\
\hline Preventive response & 95 & 4.21 & 171 & 4.23 & 107 & 4.42 & 27 & 4.48
\end{tabular}

Panel C: Age

\begin{tabular}{|c|c|c|c|c|c|c|c|c|c|}
\hline \multirow[t]{2}{*}{ Proactive ability } & \multicolumn{2}{|c|}{$\begin{array}{l}\text { (1) } 45-49 \text { years } \\
\text { old }\end{array}$} & \multicolumn{2}{|c|}{$\begin{array}{l}\text { (2) 50-54 years } \\
\text { old }\end{array}$} & \multicolumn{2}{|c|}{$\begin{array}{l}\text { (3) } 55-59 \text { years } \\
\text { old }\end{array}$} & \multicolumn{2}{|c|}{$\begin{array}{l}\text { (4) } 60 \text { years old } \\
\text { or older }\end{array}$} & \multirow[t]{2}{*}{ Difference } \\
\hline & N.P. & A.V. & N.P. & A.V. & N.P. & A.V. & N.P. & A.V. & \\
\hline Reflective response & 121 & 3.44 & 159 & 3.50 & 107 & 3.47 & 13 & 3.67 & \\
\hline Preventive response & 121 & 4.34 & 159 & 4.11 & 107 & 4.42 & 13 & 5.00 & $\begin{array}{l}1,3 、 4>2 * * * \\
4>1,3 * * *\end{array}$ \\
\hline
\end{tabular}

Panel D: Region

\begin{tabular}{llllllll}
\hline Proactive ability & \multicolumn{2}{l}{ (1)Mountain Line Area } & \multicolumn{2}{l}{ (2) Coast Line Area } & \multicolumn{2}{l}{ (3) Tun District } & Difference \\
\cline { 2 - 8 } & N.P. & A.V. & N.P. & A.V. & N.P. & A.V. \\
\hline Reflective response & 91 & 3.45 & 108 & 3.45 & 201 & 3.51 & \\
\hline Preventive response & 91 & 3.61 & 108 & 4.63 & 201 & 4.42 & $2.3>1 * * *$ \\
\hline
\end{tabular}

\subsection{Analysis of the Differences in Life Adaptation between Middle-Aged and Elderly People with Different Population Attributes}

(1) Gender:

Through the statistical values of the questionnaire, we found that gender has a significant impact on life adaptation. In the gender component, the number of males is 239 , the average is 4.226; the female is 161 , and the average is 4.169 . In the independent sample $t$ test, we used $p<0.05$ as a significant level. We found that the independent sample $t$ test of "expression demand" was $\mathrm{p}=0.006$; the independent sample $\mathrm{t}$ test of "self-overtaking demand" was $\mathrm{p}=0.000$, which reached a significant level.

(2) Education

This study found that there is no difference in the degree of life adaptation. In the academic part, the number of small people is 95 , the number of people in the middle is 171 , the number of high school is 107, and the number of junior college or above is 27 . In the single-factor variation analysis, $\mathrm{p}<0.05$ was used as the significant level, and $\mathrm{p}=0.000$ of
"Affordable Demand" ANOVA, p=0.006 of "Expression Demand" ANOVA, $\mathrm{p}=0.000$ of "Contribution Demand" ANOVA, "Impact" The demand "ANOVA p $=0.000$, "self-overtaking demand" ANOVA $p=0.000$, have reached a significant level. After further examination by Scheffe, it was found that the people in the national, middle and junior colleges paid more attention to "paying for the demand" than the high school people. In addition, the small people in the country pay more attention to "demanding demand" than the people in the middle school; the high school people are better than the middle school. People pay more attention to "expression needs"; people in small and high schools pay more attention to "contributing needs" than those in the country. People from junior colleges and colleges pay more attention to "influencing demand" than those in high schools. People pay more attention to "influencing demand"; people above junior colleges pay more attention to "self-transcending demand" than those in small, middle and high schools.

(3) Age

The study found that there are still differences in the degree of life adaptation. In the age group, the number of people aged 45 to 49 is 121 , the number of people aged 50 to 54 is 159 , and 
the number of people aged 55 to 59 is 107 . The number of people over the age of 13 is 13 . In the single factor variance analysis, $\mathrm{p}<0.05$ was used as a significant level. Found $\mathrm{p}=$ 0.000 for ANOVA, $\mathrm{p}=0.000$ for "Expression Demand" ANOVA, $\mathrm{p}=0.000$ for "Contribution Demand" ANOVA, $\mathrm{p}=$ 0.000 for "Affected Demand" ANOVA, $p=0.000$ for "self-overtaking demand" ANOVA 0.000, all have reached a significant level. After further examination by Scheffe, it was found that: people aged 50-54, 55-59 and over 60 pay more attention to "demand" than those aged 45-49; people over 60 years old are 45 49 years old, 50 54 years old 5, 5 59 years old people pay more attention to "expression needs", and other 45-49 year olds pay more attention to "expression needs" than people aged 50-54 and 55-59, and people aged 55-59 More people than people aged 50-54 pay more attention to "expression needs"; people aged 45-49, 55-59 and over 60 pay more attention to "contribution needs" than those aged 50-54, and others over 60 years old People aged 55-59 pay more attention to "contribution needs"; people aged $45-49,55-59$, and 60-year-old pay more attention to "influencing demand" than those aged 50-54, and people over 60 are over 45 . People aged $\sim 49$ and 55-59 pay more attention to "influencing demand"; people over the age of 60 pay more attention to "self-transcendence" than those aged 45-49 and 50-54, and those aged 55-59 People aged 50 to 54 pay more attention to "self-transcending demand."

(4) Area

The study found that there are still differences in the degree of adaptation to life. In the regional part, the number of
Mountain Line Area is 91, the number of Coast Line Area is 108 , and the number of the Tun District is 201. In the single factor variance analysis, $\mathrm{p}<0.05$ was used as a significant level. $\mathrm{P}=0.000$ for "Ahead-to-demand" ANOVA, $\mathrm{p}=0.000$ for "Expression Demand" ANOVA, $\mathrm{p}=0.000$ for "Contribution Demand" ANOVA, $p=0.000$ for "Affected Demand" ANOVA, $\mathrm{p}=0.000$ for "self-overtaking demand" ANOVA 0.000 , all have reached a significant level. Further examination by Scheffe found that the people in the Coast Line Area pay more attention to "paying for demand" than those in the Mountain Line Area and the Tun District, and the people in the Tun District pay more attention to "paying for demand" than those in the Mountain Line Area; People in the Coast Line Area pay more attention to "expression needs" than people in the Mountain Line Area and the Tun District; people in the Coast Line Area pay more attention to "contribution needs" than people in the Mountain Line Area and the Tun District in Taichung, and the Tun District People in the Mountain Line Area pay more attention to "contribution needs"; people in the Coast Line Area and the Tun District pay more attention to "influencing demand" than people in the Mountain Line Area; people in the Coast Line Area are more likely than the Mountain Line Area and the Tun District. People pay more attention to "self-transcending demand." The results of the analysis of differences in life adaptation among middle-aged people with different population attributes are presented in Table 3.

Table 3 Analysis of differences in life adaptation among middle-aged and elderly people with different population attributes

\begin{tabular}{|c|c|c|c|c|c|}
\hline \multicolumn{6}{|l|}{ Panel A: Gender } \\
\hline \multirow{2}{*}{$\begin{array}{l}\text { Difference in life } \\
\text { adaptation }\end{array}$} & \multicolumn{2}{|c|}{ Male } & \multicolumn{2}{|c|}{ Female } & \multirow[t]{2}{*}{ Difference } \\
\hline & Number of people & Average Value & Number of people & Average Value & \\
\hline Coping with demand & 111 & 4.43 & 285 & 4.47 & \\
\hline Express demand & 111 & 3.98 & 285 & 3.80 & $\mathrm{M}>\mathrm{F}^{* *}$ \\
\hline $\begin{array}{l}\text { Contributing } \\
\text { demand }\end{array}$ & 111 & 4.17 & 285 & 4.20 & \\
\hline Influence demand & 111 & 4.26 & 285 & 4.27 & \\
\hline $\begin{array}{l}\text { Self-transcending } \\
\text { demand }\end{array}$ & 111 & 4.07 & 285 & 3.73 & $\mathrm{M}>\mathrm{F}^{* * *}$ \\
\hline Adaptation of life & 111 & 4.22 & 285 & 4.16 & \\
\hline
\end{tabular}

Panel B: Education

\begin{tabular}{|c|c|c|c|c|c|}
\hline $\begin{array}{l}\text { Difference in life } \\
\text { adaptation }\end{array}$ & $\begin{array}{l}\text { (1) Elementary } \\
\text { school }\end{array}$ & (2) Secondary & $\begin{array}{l}\text { (3) High school } \\
\text { (Vocational } \\
\text { college) }\end{array}$ & $\begin{array}{l}\text { (4) College or } \\
\text { above }\end{array}$ & Difference \\
\hline
\end{tabular}

\begin{tabular}{|c|c|c|c|c|c|c|c|c|c|}
\hline & \\
\hline & N.P. & A.V. & N.P. & A.V. & N.P. & A.V. & N.P. & A.V. & \\
\hline \multirow{3}{*}{ Coping with demand } & & & & & & & & & 1、2、 \\
\hline & 95 & 4.72 & 171 & 4.53 & 107 & 4.07 & 27 & 4.48 & $4>3 * * *$ \\
\hline & & & & & & & & & $1>2 * * *$ \\
\hline Express demand & 95 & 3.87 & 171 & 3.81 & 107 & 4.04 & 27 & 4.17 & $3>2 * *$ \\
\hline $\begin{array}{l}\text { Contributing } \\
\text { demand }\end{array}$ & 95 & 4.27 & 171 & 4.03 & 107 & 4.33 & 27 & 4.27 & $1 、 3>2 * * *$ \\
\hline Influence demand & 95 & 4.53 & 171 & 4.18 & 107 & 4.10 & 27 & 4.48 & $\begin{array}{l}1 、 4>3 * * * \\
1>2 * * *\end{array}$ \\
\hline
\end{tabular}




\begin{tabular}{llllllllll}
\hline $\begin{array}{l}\text { Self-transcending } \\
\text { demand }\end{array}$ & 95 & 3.97 & 171 & 3.85 & 107 & 3.90 & 27 & 4.48 & $\begin{array}{l}4>1 、 2 、 \\
3 * * *\end{array}$ \\
\hline Panel C: Age & & &
\end{tabular}

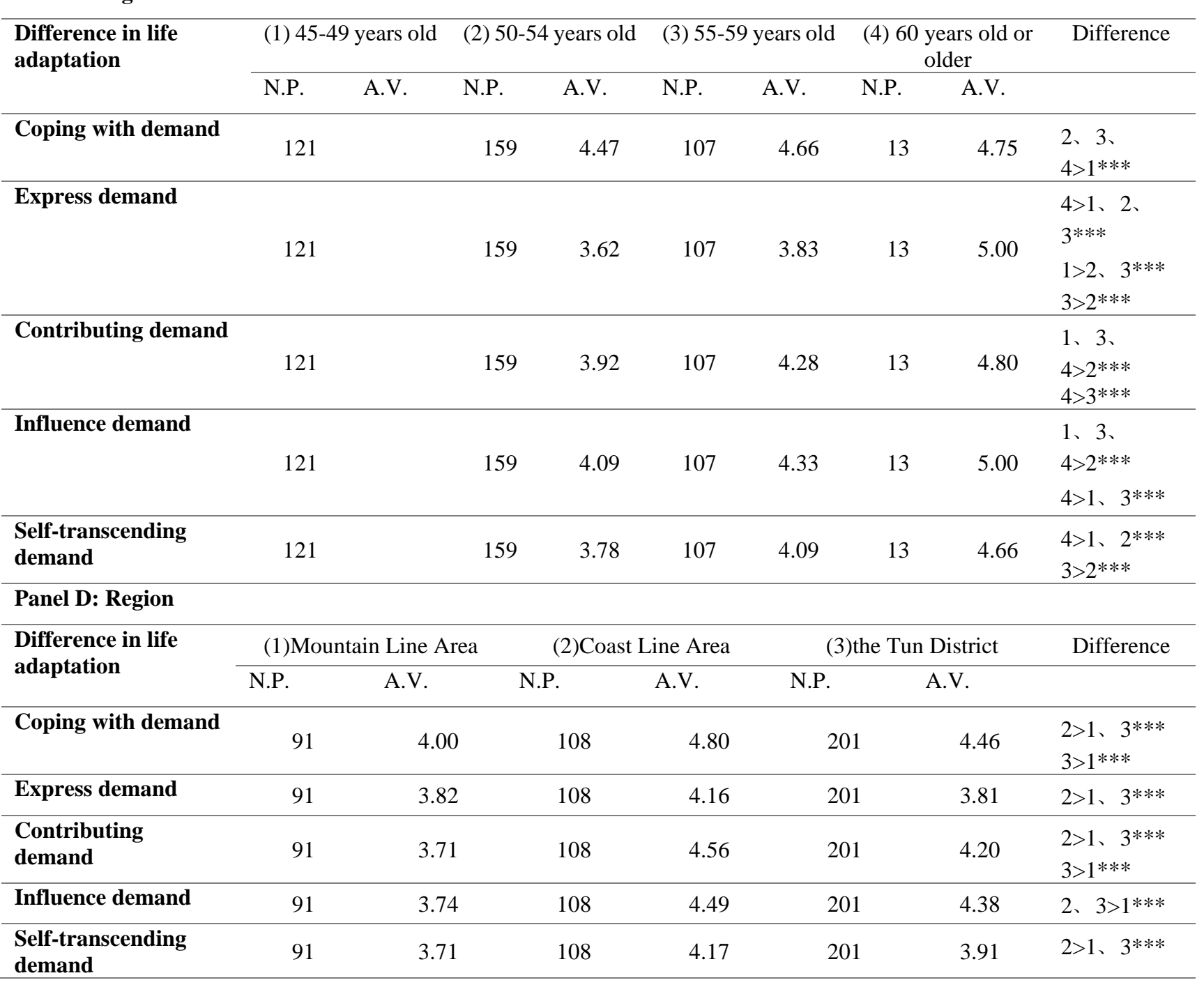

\subsection{Exploring Learning Topics and Prospects have Predictive Power in Response to Life Adaptation}

This study uses SPSS statistics (Wu Minglong, 2006) [8]to analyze the relationship between learning topics and prospects in response to life adaptation, and to analyze the regression model. It is found that the theme of life learning and prospectiveness are predictive because of the relationship with life adaptation. Proactive ability facets are considered to be self-variant, and life adaptation is dependent on variables to test their impact on "life adaptation". From the test results, it was found that the Learning Topics and prospects had a significant positive impact on response to life adaptation $(\beta=2.716, P<0.001 ; \beta=1.276, P<0.001)$, and the regression model reached a significant level. The results are shown in Table 4 . The regression equation obtained by the regression analysis method: Satisfaction $=1.276+0.047 *$ Learning subject $+0.033 *$ Proactive ability, indicating that the higher the requirements of the middle and senior age on the subject of learning and the prospective factors, the higher the life adaptation, as follows:

Table 4 Regression analysis of Learning Topic and prospects in response to life adaptation

\begin{tabular}{ccc}
\hline Independent Variable & Mode1 Regression Coefficients & Mode 2 Regression coefficients \\
\hline Constant & $2.716^{* * * *}$ & $1.276^{* * *}$ \\
\hline Learning Topics & $0.058^{* * * *}$ & $0.047^{* * *}$ \\
\hline
\end{tabular}




\begin{tabular}{ccc}
\hline Proactive ability & & $0.033^{* * *}$ \\
\hline $\mathbf{R}^{\mathbf{2}}$ & $0.109^{* * * *}$ & $0.451^{* * *}$ \\
\hline Adj $\mathbf{R}^{\mathbf{2}}$ & $0.107^{* * * *}$ & $0.449 * *$ \\
\hline $\mathbf{F}$ & 48.449 & 19.744 \\
\hline
\end{tabular}

\section{CONCLUSION}

This study is aimed at the Proactive ability of senior students in Taiwan Adult Learning Center (Bode, DeRidder, Kuijer \& Bensing, 2007) [9], learning topics and life adaptation (Hoskins, 2002) [10]. It is hoped that Proactive ability and learning subject surveys can help seniors. The learner's life adapts to let them face more efforts in the later life, and the summary is summarized in this study, as follows:

This study is for adult learners. In the hypothesis 1 . Presenting the population attribute has a significant relationship with the learning theme of middle-aged and older students. The significant attribute result is 1 . Gender: In the "safety of life" part, males are more female than females. Significantly high; women are more prominent than men in the "interpersonal communication" and "contribution services". 2. Education: In the "sports health care" section, colleges and universities are more significant than the national, middle and high schools (jobs); in the "spiritual growth" part, colleges and above are still more prominent than the middle and high schools (jobs); The part of the college is more significant than the national, middle and high school (job); but in the part of "interpersonal communication", the national small is more prominent than the middle school and high school. 3. Age: In the "safety of life" and "spiritual growth", 60 years old and older are more significant than 45-49 years old, 50-54 years old, 55-59 years old; in the "sports health care" part, 55-59 years old 45-49 years old, 50-54 years old is remarkable; in the "interpersonal communication" part, it is 55-59 years old, 60 years old or older is more significant than 45-49 years old, 50-54 years old; in the "contribution service" part, it is $45-49$ years old, 55-59 years old than 50-54 years old, 60 years old or older. 4 . Area: In the sections of "Life Safety" and "Interpersonal Relationships", both the Coast Line Area and the Tun District are more prominent than the Mountain Line Area; in the "Sports Health Care" and "Contribution Services" sections, both are Mountain Line Area. The Coast Line Area is more prominent than the Tun District; the part of "Spiritual Growth" is that the Coast Line Area is more prominent than the Tun District. In hypothesis 2. Presenting population attributes has a significant relationship with the Proactive ability of middle-aged and older students. The significant attribute results are 1. Gender: none of the findings are significant; 2. Education: Found a "preventive response" ANOVA $p=0.022$, There is a significant level; 3 . Age: found that the "prevention response" ANOVA $\mathrm{p}=0.000$, has reached a significant level, 45-49 years old, 55-59 years old, 60 years old and above than 50-54 years old to reach a significant level; 4. Area : Found that "preventive response" ANOVA $p=0.000$, there is a significant level, Coast Line Area, the Tun District is significantly higher than the Mountain Line Area. In the hypothesis 3. The demographic attributes are predictive of the relationship between the middle-aged and older students, and the significant attribute results are significant in 1. gender: "expression demand" and "self-transcend demand"; : In the "pay-as-you-go" component, the national, junior and junior colleges are more prominent than the high school (job). In the "Expression of Demand" section, the high school (job) is more prominent than the middle school. The national small and high school (vocational) level is even more remarkable than that of the middle school. The "influencing demand" part, the national junior college, the junior college or higher is higher than the high school (service), and the "self-transcendence demand" part is higher than the national junior college and the middle school. , high school (job) is even more remarkable; 3 . Age: "paying demand" part, 50-54 years old, 55-59 years old, 60 years old and above is more significant than 45-49 years old, "Expression demand" part More than 60 years old, 45-49 years old, 50-54 years old, 55-59 years old, even more significant, "contribution demand" part, 45-49 years old, 55-59 years old, 60 years old or older than $50-54$ years old A significant level of "affecting demand", 45-49 years old, 55-59 years old, 60 years old and above is more significant than 50-54 years old," The section on self-transcendence needs to be more than 60 years old and older than 45-49 years old and 50-54 years old. 4. Area: "Coping with demand", "Expressing demand", "Contributing demand" and "Self-surpassing demand" The Coast Line Area is significantly more important than the Mountain Line Area and the Tun District. The "Affected Demand" section, the Coast Line Area and the Tun District are significantly higher than the Mountain Line Area.

\section{REFERENCES}

[1] Gan,Y.,Hu,Y.,\&Zhang, Y., 2010, Proactive and preventive coping in adjustment to college. The Psychological Record, 60(4),643-657.

[2] McClusky, H.Y., 1987, Motivation and personality.New York:Harper and row.

[3] Maslow, A. H.,1971 ,The Farther Reaches of Human Nature. New York: ViKing.

[4] Sohl,S.J., \&Moyer, A.,2009, Refining the conceptualization of a future-oriented self-regulatory behavior:proactive coping. Personality\&Individual Differences,47(2),139-144.

[5] Wei, Hui-Chuan, 2015, Adult Education Administration Program Development, Xinbei: National Air University.

[6] Zhang Shaoxun,2003,SPSS For Windows Statistical Analysis - Elementary Statistics and Advanced Statistics, Taipei City: Songgang Computer Books.

[7] Settersten,R.A., 2006, Aging and the life course.In .H.Binstock\&L.K.Georgre(Eds.), Handbook of aging and social sciences(6th eds.)(pp.3-16)San Diego:Academic Press. 
[8] Wu Minglong, 2006,SPSS Statistical Application Learning Practice: Questionnaire Analysis and Applied Statistics, Third Edition, Taipei City: Zhicheng Digital Technology Co., Ltd.

[9]

Bode,C.,DeRidder,D.,Kuijer,R.G.,\&Bensing,J.,2007,Effec ts of an intervention promoting proactive coping competencies in middle and late adulthood. The erontologist,47,42-51.

[10] Hoskins,I.,A global perspective on active and health ageing: current \& future trends. Retrieved from.

http://www.elderlycommission.gov.hk/en/programmes/20 02symposium/proceeding/10speaker_irene.pdf. 